\title{
Outcome of surgical treatment of degenerative lumbar spinal stenosis.
}

\author{
Bishnu Babu Thapal, Sushil Rana Magar', Pankaj Chand ${ }^{1}$, Bachhu Ram K.C. ${ }^{1}$ \\ ${ }^{1}$ Department of Orthopaedics, Shree Birendra Hospital.
}

\begin{abstract}
Introduction: Spinal stenosis mostly occur in lumbar spine and causes back pain, leg pain \& neurogenic claudication. Although conservative treatment is mainstay, decompression with or without fusion (with or without instrumentation) can be considered in non-responsive cases. However, long term outcome of the surgery is controversial. The aim of our study was to analyze the outcome of surgery in lumbar spinal stenosis in terms of post-operative pain and claudication distance.
\end{abstract}

Methods: A prospective analysis of patients who underwent decompression or decompression with fusion (with or without instrumentation), after failure of 3-6 months conservative treatment, for lumbar spinal stenosis were conducted. Only those who were operated and followed up for at least two years were included.Their preop and postop VAS score and walking distance compared.

Results: Of 22 cases enrolled in this study, VAS score was improved in 21 patients and walking distance increased. Only one patient complained of increase in pain score at 24 months.

Conclusion: Operative management is a good option for selected patients, 21 out of 22 have improved VAS and claudication distance in our study

Keywords: stenosis; decompression; fusion.

\section{INTRODUCTION}

Lumbar spinal stenosis is defined as a condition involving any type of narrowing of spinal canal nerve roots canals or tunnels of intervertebral foramina ${ }^{1}$. As elderly population is growing worldwide degenerative Lumbar spinal stenosis (LSS) has become one of the most frequent indication for spine surgery ${ }^{2}$. Spinal stenosis mainly causes back pain, leg pain and neurogenic claudication. Many patients with severe symptoms do not respond to conservative treatments and surgery must be considered in these cases. Although surgery for spinal canal stenosis is frequently done procedure, long terms results of surgery are not well understood. About 20-40 \% patients have been reported to be unsatisfied with result due to residual symptoms after surgery ${ }^{3}$. There are very few literature in our region and almost none in Nepal reporting outcome of lumbar spine stenosis surgery. The aim of this prospective case series is to share the outcome at our center.

\section{METHODS}

This prospective study was conducted at Shree Birendra Hospital from October 2010 to October 2013. A total of 360 patients were diagnosed as spinal canal stenosis (clinically and radiologically) during the study period. A standard physiotherapy protocol was instituted to all of them and they were asked to comply to the protocol and continue for at least 6 months. Only those who have severe symptoms and no improvement after 6 months of physiotherapy were offered a surgical option. A total of 22 patients provided informed written consent to undergo surgery and followed up for two years. Surgeries were either decompression or decompression

\section{Correspondence:}

Bishnu Babu Thapa

Department of Orthopedics, Shree Birendra Hospital.

Email: drbishnubthapa@gmail.com 
with fusion (with or without instrumentation). Patients who had stenosis, without listhesis and instability, underwent only decompression. Stenosis with listhesis underwent decompression and posterior fusion along with instrumentation. Patients having listhesis with instability were managed with decompression and $360^{\circ}$ fusion. All the patients mobilized early as they started tolerating pain, usually 3-5 days. They were reviewed at 3, 6, 12 and 24 months. VAS and claudication distance were measured at each followup. The data were analysed in SPSS version 21.

\section{RESULTS}

Duration of onset of symptoms were 6 months to 7 years (mean 18 months). Pre-op clinical sign and symptoms were low back pain (95\%), leg pain (55\%), Neurogenic claudication (30\%), sensory change (10 $\%)$, motor weakness (5\%). The demographic feature of our study population was shown in Table 1.

Table 1. Demographics of patients.

\begin{tabular}{|ll|l|}
\hline Age & Range \\
& Mean & 45-73 years \\
Sex $\quad$ Male & 12 Years \\
& female & 10 \\
\hline Profession & 10 \\
Housewives & Retired soldiers & 8 \\
& Unemployed & 4 \\
\hline Onset of symptoms & 6 months -7 years (Mean) \\
\hline
\end{tabular}

There were 12 patients with single level decompression and 7 patients with 2 level and 3 patients with 3 level decompressions. The predominant levels of stenosis were L4-L5 followed by L3-L4 (Table 2).

Table 2. level of decompression and number of patients.

\begin{tabular}{|l|l|l|l|}
\hline $\begin{array}{l}\text { No of decompression } \\
\text { level }\end{array}$ & one & two & three \\
\hline No of patients & 12 & 7 & 3 \\
\hline
\end{tabular}

Fifteen patients had decompression and fusion with posterior instrumentation, three patients had $360^{\circ}$ fusion, three had only decompression, and one patient had decompression and fusion only.
There were few intraop and post op complications. One patient had incidental durotomy which was managed with tight closure of wound and by keeping the patient supine for two weeks. Three patients had infection, one had superficial infection, which was managed with antibiotics, one had deep infection 8 months after surgery and diagnosed as pott's spine, another one had discitis treated with 6 weeks of IV antibiotic therapy.

The VAS and claudication improved in subsequent follow up except in one patient who persistently complained of pain and no improvement in claudication distance (Table 3).

\begin{tabular}{|l|l|l|l|l|l|}
\hline Characteristics & \multicolumn{1}{|c|}{ Preop } & 3 months & $\mathbf{6}$ months & $\begin{array}{c}\text { 12 } \\
\text { months }\end{array}$ & $\begin{array}{l}\text { 24 } \\
\text { months }\end{array}$ \\
\hline VAS & $5 \pm 1.5$ & $3 \pm 1.5$ & $2 \pm 1$ & $2 \pm 1$ & $2 \pm 1$ \\
\hline $\begin{array}{l}\text { C l a ud ic a tion } \\
\text { Distance }\end{array}$ & $100 \pm 100$ & $500 \pm 200$ & $800 \pm 200$ & $\begin{array}{l}100 \\
200\end{array}$ & $\begin{array}{l}1000 \pm \\
200\end{array}$ \\
\hline
\end{tabular}

\section{DISCUSSION}

Lumbar spinal stenosis is a major cause of low back pain and leg pain in the elderly and one of the most common indications for spinal surgery. Despite the widespread surgical treatment for lumbar spinal stenosis, long term result remains unknown. Decompression surgeries improve in leg pain and walking ability but poorer improvement in low back pain ${ }^{1}$.

Several authors have shown good to excellent outcomes for most patient without much deterioration over time $^{5}$. On the other hand, other authors have reported that outcomes are not so good and patients deteriorate over time ${ }^{7-10}$. Most of these studies were conducted in western countries. No studies have been reported from our own country.

The current study evaluated two years outcome in 22 patients operated for degenerative lumbar spinal stenosis. The patients were followed up at standard interval and symptoms severity was measured by visual analogue score (VAS) and walking distance. We can see the gradual improvement in VAS score and claudication distance in subsequent follow up which steadied after one year. The statistical value of our case series may not be very high but this can be a pilot study and a well-organized randomized control trial has to be performed in future.

A total of $95 \%$ patients had back pain and $55 \%$ had leg pain. Similar findings were reported by Par et al, other studies also showed majority of the patients had back pain (>90\%), leg pain $(>60 \%)^{4,5}$ and symptoms prior to surgery for upto 14 years 5 . 
L4-L5 was the most commonly involved level, followed by L3-L4. Half of our patient had one level decompression and another half required multiple level decompressions. Similar to our results, Cornefiord M et al, also found L4-L5 was the commonest level and most patients had single level decompression in their series $^{6}$.

Stromqvist $\mathrm{F}$ and his colleague found dural lesion in $7.4 \%$ of their cases ${ }^{7}$. They mentioned that, advanced age, previous surgery and smoking were risk factors for sustaining a lesion, however did not affect the one year outcome negatively ${ }^{7}$.We had one case of incidental durotomy, which was managed conservatively. Incidental durotomy in primary lumbar decompression surgery can be successfully managed without primary suture repair with no adverse effect on surgical outcome in long term ${ }^{8}$. The incidence of dural lesions increased with number of levels decompressed from $5.1 \%$ in one level decompression to $11.5 \%$ when four or more levels were decompressed ${ }^{7}$.

The infection rate of spinal surgeries was from 0.7 to $11.9 \%$ depending on the diagnosis and complexity of the procedure ${ }^{9-11}$. More complicated procedures result in higher infection rates. The rate of infection after simple discectomy or laminectomy is $1 \%$, whereas a spinal fusion has rate of $2-5 \%$. The addition of an implant to a spinal fusion increase the infection risk further, $2.4-8.5 \%$. The most frequently infected spinal fusion is a combined anterior /posterior procedure 9 . In our series we had $14 \%$ infection rate, one case of discitis, one superficial infection and one deep infection. The infection rate was high compared to literature, which may be attributed to the theater condition in our part of the world.

In decompression surgeries, There were significant improvement in back and leg pain at all review period (Table 3). Anjarwalla NK and his colleagues reported some deterioration in pain level after 5 years of surgery, but still pain were significantly improved from baseline level in their study ${ }^{12}$. In other study by Anne F, there was significant reduction in mean leg pain of $3.6 \pm 2.5$ points $(p<0.05)$ from pre op to 2 months post-operative period, after which there was no significant further change upto 5 years follow up and similar results were mentioned for back pain in the same study ${ }^{13,14}$. In our study there was significantly improved mean VAS score for back and leg pain from $5 \pm 1.5$ preoperatilvely to $2 \pm 1$ at two years followup.

There were various parameter to measure the disability due to spinal stenosis, commonly performed was
Oyster Disability Index (ODI). But due to social reasons and most of our patients were uneducated, we were not able to apply ODI. Pre and post op walking distance were measured to assess improvement in disability. All of our patient had claudication distance less than $100 \pm 100$ meters preoperatively which improved to $1000 \pm 200$ at 2 years follow up.

\section{CONCLUSION}

We conclude that decompression surgery is a good option for selected patients who did not respond well to conservative treatment. Surgical treatment improved the VAS and claudication distance.

\section{REFERENCE}

1. Arnoldi CC, Brodsky AE, Chauchoix J, et Al. Lumbar spinal stenosis and nerve root entrapment syndromes definitation and classification. Clinorthop. 1976;115:4-5.

2. Mazanec DJ, Podichetty VK, Hsia A. Lumbar canal stenosis: start with nonsurgical therapy. Cleve Med. 2002;69:909-17.http://dx.doi. org/10.3949/ccjm.69.11.909

3. Aono H, Iwasaki M, Ohwada T et al. Surgical outcome of drop foot caused by degenerative lumbar disease. Spine. 2007;32:262-6.http:// dx.doi.org/10.1097/01.brs.0000259922.82413.72

4. Halit C, Ramazan AK, Osman NT. Et.al. Midterm outcome after unilateral approach for bilateral decompression of lumbar spinal stenosis: 5 years propective study. Eur Spine J. 2007;16:2133-42. http://dx.doi.org/10.1007/s00586-007-0471-2

5. Par S, Antti m, Markku H, et.al. Long term results of surgery for lumbar spinal stenosis: a randomized controlled trial. Eur Spine J. 2011;20:1174-81.http://dx.doi.org/10.1007/ s00586-010-1652-y

6. Cornefiord M, Byrod G, Brisby H, et. al. A long term(4-12year) follow up study of surgical treatment of lumbar spinal stenosis. Eur spine J. 2000;9:563-70.http://dx.doi.org/10.1007/ s005860000161

7. Stromqvist F, Jonsson B, Stromqvist B. Dural lesions in decompression for lumbar spinal stenosis: incidence, risk factors and effect on outcome. Eur spine J. 2012;21:825-8.http:// 
MJSBH January-June 2015|Vol 14| Issue 1

dx.doi.org/10.1007/s00586-011-2101-2

8. Grannum S, Patel M, Attar F. Dural tears in primary decompressive lumbar surgery. Is primary repair necessary for a good outcome? Eur Spine J. 2014;23:904-908.http://dx.doi. org/10.1007/s00586-013-3159-9

9. Fang $A, H u$ SS, Endres $N$, et.al.Risk factor for infection after spinal surgery. Spine. 2005;30:1460-5. http://dx.doi.org/10.1097/01. brs.0000166532.58227.4f

10. Massie JB, Heller JG, Abitbol JJ, et.al. Postoperative posterior spinal wound infections. Clinorthop relat res. 1992;284:99-108. http:// dx.doi.org/10.1097/00003086-199211000-00013

11. Weinstein MA, Mccabe JP, Cammisa FP. Postoperative spinal wound infection:A review of 2391 consecutive index procedure.
$J$ spinal disord. 2000;13:422-6. http://dx.doi. org/10.1097/00002517-200010000-00009

12. Anjarwalla NK, Brown LC, McGregor AH. The outcome of spinal decompression surgery 5 years on.Eur spine J. 2007;16:1842-7.http://dx.doi. org/10.1007/s00586-007-0393-z

13. Anne F, Mannion $R$, Denzler J. Five-years outcome of surgical decompression of the lumbar spine without fusion. Eur Spine J. 2010;19:188391. http://dx.doi.org/10.1007/s00586-010-15352

14. Daniel A, Jones R, Wafai AM. Improvement in low back pain following spinal decompression observational study of 119 patients.Eur Spine J.2014; 23:135-41. http://dx.doi.org/10.1007/ s00586-013-2964-5 